\title{
Los desafíos de la democracia constitucional en América Latina: entre la tentación populista y la utopía neoconstitucional
}

Este comentario, junto a los documentos que analiza, está disponible en www.anuariocdh.uchile.cl

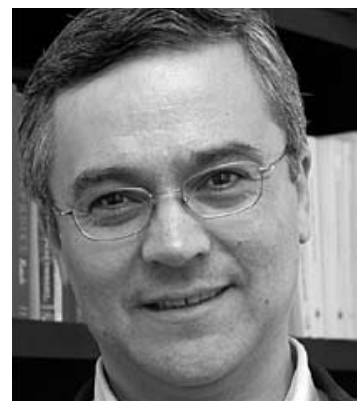

\section{Javier Couso Salas}

Licenciado en Ciencias Jurídicas y Sociales por la P. Universidad Católica de Chile. Doctor en Derecho por la Universidad de California en Berkeley (EE.UU.). Miembro del Comité Ejecutivo de la Asociación Internacional de Derecho Constitucional. Miembro del directorio de la Corporación de Expansiva. Profesor titular de la Facultad de Derecho de la Universidad Diego Portales.

javier.couso@udp.cl

\section{RESUMEN}

A dos décadas desde que América Latina se embarcara en procesos de transición democrática el balance es decididamente mixto. Por una parte, debe celebrarse el que el régimen democrático se considere como el único mecanismo legítimo de gobierno, así como la sensible reducción en los niveles de pobreza e indigencia de la región. Por otra, preocupa la persistencia en no pocos países de la región de prácticas autoritarias (como la ejecución extrajudicial de individuos por parte de organismos policiales) y la porfiada persistencia de niveles intolerables de inequidad y exclusión. Estos últimos flagelos han suscitado diversas reacciones, como la tentación populista (de derecha o de izquierda) y la salida 'neoconstitucional' (que pone toda su esperanza en el rol emancipador de la justicia constitucional). En este ensayo, se analizan las limitaciones de estas dos respuestas a la crisis de la democracia latinoamericana, concluyéndose que la profundización de la misma pasa por el gradual y laborioso camino de insistir en institucionalizar prácticas como los controles recíprocos entre los poderes del Estado, la movilización de la sociedad civil y la independencia de la judicatura.

\section{Dos décadas de democracia electoral en América Latina (1990-2010)}

Cuando han transcurrido ya dos décadas desde que la Ilamada "tercera ola democrática" ${ }^{1}$ comenzara a desplegarse con fuerza en América Latina, el balance del curso de la democracia en la región es decididamente mixto. Por una parte, no cabe duda que los más de veinte años en

1 Esta noción fue introducida por el cientista político Samuel Huntington para referirse al proceso de diseminación de regímenes políticos democráticos entre las décadas de los ochenta y comienzos del noventa. Durante esos años, más de 30 países iniciaron procesos de transición a la democracia, doblando el número de sistemas de tal índole que existían hasta ese momento. De acuerdo a Huntington, la primera "larga ola" democrática habría comenzado a comienzos del siglo XIX, con la expansión del sufragio en los Estados Unidos, extendiéndose hasta 1926, cuando el número de democracias alcanzó a 29. La "segunda ola democrática" habría partido inmediatamente después de la Segunda Guerra Mundial, y hasta 1966, cuando se registraron un total de 36 sistemas democráticos en el mundo. Véase HUNTINGTON, Samuel. La Tercera Ola. La democratización a finales del siglo XX, Barcelona, Paidós, 1994. 
que el sistema democrático ha sido considerado como 'the only game in town' ${ }^{2}$ representan un verdadero hito en una región habituada a gobiernos impuestos por poderes coloniales, grupos oligárquicos o aparatos militares. Por otra, la calidad de los sistemas democráticos de buena parte de América Latina deja mucho que desear, lo que se ha traducido en una dramática caída de la confianza ciudadana en las instituciones políticas y en la convicción por parte de una mayoría de los latinoamericanos que "los gobiernos sirven a las elites más que a la mayoría" 3 .

El "lado lleno del vaso" del estado de la democracia en América Latina es que en estas últimas dos décadas los casos de regresión autoritaria han sido escasos y, cuando han ocurrido, han encontrado un fuerte repudio entre los gobiernos y la ciudadanía de la región ${ }^{4}$. En efecto, y como lo demuestra el último episodio de abierto desconocimiento de la democracia -el golpe de Estado propinado contra el presidente constitucional de Honduras, Manuel Zelaya, el 28 de junio de 2009-, las rupturas autoritarias representan ahora algo inaceptable para todo el espectro ideológico. Esto explica por qué el golpe en Honduras fue rechazado por países con gobiernos de cuño ideológico tan diferentes como los de Colombia y Venezuela.

Contrastando con el innegable progreso logrado en la región en materia de estabilidad democrática, las últimas dos décadas registran generalizadas prácticas de deslealtad con las reglas constitucionales más elementales, como las que garantizan los derechos fundamentales de las personas o las que impiden la reelección reiterada de los gobernantes. Así, a pesar de que los gobiernos ahora deben rendir cuentas ante la ciudadanía periódicamente (en tiempo de elecciones), han persistido las prácticas de abuso de poder, corrupción y socavamiento de las instituciones públicas que han caracterizado a América Latina desde el proceso de independencia.

En este ensayo, luego de una revisión de la trayectoria de la democracia en América Latina en los últimos veinte años, en particular desde el punto de vista de su relación con los derechos humanos y el estado constitucional de derecho, se analiza críticamente la noción que la respuesta a los problemas de la democracia en la región reside en la articulación e implementación de un nuevo modelo de estado democrático de derecho, como, por ejemplo, el ofrecido por el neoconstitucionalismo. Más que un problema conceptual lo que se requiere es afinar el diagnóstico acerca de los problemas de implementación del ideario democrático-constitucional, para luego fijar las reformas prioritarias que vayan progresivamente abordando los problemas más urgentes que enfrenta la democracia en la región.

\section{La consolidación del ideario constitucional-democrático}

En la actualidad, la línea de base de la situación política en América Latina es la inevitabilidad de la elección democrática de las autoridades y del respeto de los derechos fundamentales de los individuos. Respecto al primer punto, hoy por hoy es inconcebible que los gobernantes sean

2 Esta coloquial expresión inglesa, que se puede traducir al castellano como "el único juego en el pueblo", se utiliza entre especialistas en consolidación democrática para señalar la idea que la democracia es el único mecanismo aceptado para escoger autoridades políticas en la región.

3 Reporte de Latinobarómetro citado en CEPAL. Social Panorama of Latin America. ONU, 2009, p. 19 .[En línea] http:// www.eclac.org/publicaciones/xml/0/37840/PSI2009-Sintesis-Lanzamiento.pdf. [Consulta: 15 de marzo de 2010]. Traducción del autor.

4 Sin perjuicio de los ocasionales golpes de Estado que han afectado a la región, como el propiciado por Fujimori en Perú (1993) y el de Honduras (2009), los especialista en este tipo de incidentes en América Latina, Fabrice Lehoucq y Aníbal Pérez-Liñán, reportan que: "Aun cuando la temprana terminación de los gobiernos no ha desaparecido en la región (Hochstetler, 2006; Negretto, 2006; Pérez-Liñán, 2007), los militares han permanecido en sus barracas desde el inicio de la Tercera Ola democrática...". Véase LEHOUCQ, Fabrice y PÉREZ, Aníbal. Regimes, Competition, and Military Coups in Latin America. En: Encuentro Anual de la American Political Science Association (APSA), Toronto, Canadá, 2009, p. 5. Traducción del autor. 
impuestos al pueblo por métodos antidemocráticos y existe una abrumadora evidencia que avala la impresión que en los últimos veinte años los latinoamericanos han elegido a sus gobernantes en procesos electorales limpios y abiertos a diversas opciones políticas. Esto último representa un logro nada despreciable en una región en que las formas más mínimas de democracia electoral fueron tradicionalmente muy difíciles de consolidar. En relación con el segundo, en el último tiempo también se ha ido consolidando en Latinoamérica la adhesión a la idea de que la mayoría debe respetar los derechos fundamentales de las minorías, aspecto básico de la democracia constitucional.

Este panorama contrasta fuertemente con lo que ocurría hasta las décadas de los sesenta o setenta, en que buena parte de la izquierda y la derecha latinoamericanas exhibían una gran distancia ideológica respecto de la propia noción de democracia constitucional, esto es, de un régimen en que la mayoría del pueblo elige a los gobernantes y donde éstos someten su actuación a los límites establecidos por la Constitución y las leyes, en particular el respeto a los derechos fundamentales.

En el caso de los sectores de izquierda esta distancia se tradujo en su menosprecio de lo que llamaban "democracia burguesa", considerada por ellos como un pobre sucedáneo de la "democracia popular". Esta aproximación al asunto se vinculaba al antiguo planteamiento que la tradición marxista hiciera respecto de la radical incompatibilidad de la democracia con el capitalismo ${ }^{5}$. De acuerdo a esta aproximación al asunto, una genuina democracia sólo es posible en el contexto de una economía socialista ya que de lo contrario aquella deviene en una ilusión que distrae las energías del pueblo respecto de la verdadera emancipación, la destinada a terminar con la "esclavitud del trabajo asalariado" 6 .

El desdén por la democracia electoral en condiciones de producción capitalista, que era común a parte importante de la izquierda mundial, se vio potenciado en América Latina por la convicción de que los límites constitucionales a los gobiernos generados democráticamente no beneficiaban más que a los sectores conservadores, que lograban así perpetuar su control sobre aspectos importantes del orden social tradicional, amparados en cartas constitucionales introducidas en épocas en que el sufragio había estado reservado a las clases propietarias. De acuerdo a esta aproximación, el derecho -incluido el derecho constitucional- aparecía no como un límite saludable al poder de los gobernantes, sino como un verdadero "obstáculo al cambio social", en la legendaria formulación de Novoa Monreal ${ }^{7}$. De ahí que, aun aquellos que dentro de la izquierda valoraban la democracia electoral, miraban con escepticismo los límites al poder que el constitucionalismo democrático prescribía. Para estos sectores, no dejaba de ser irónico que -luego de décadas de lucha por ampliar el sufragio a los sectores más desposeídos- justo cuando el poder soberano era (¡por fin!) ejercido por la mayoría del pueblo, su alcance se viera restringido por límites impuestos por un orden constitucional gestado en épocas oligárquicas.

Esta poderosa -y a decir verdad, no demasiado exagerada- crítica a la democracia liberal fue luego potenciada por la influyente revolución cubana, que en un comienzo pareció ofrecer una mejor alternativa al engorroso esquema de mayorías populares "atadas" por un sistema constitucional elaborado por el orden tradicional. En comparación con este sistema tan amañado, la revolución cubana aparecía como un modelo infinitamente más directo y efectivo. En efecto, en lugar de los

\footnotetext{
Véase SCHWARZMANTEL, John y BLAUG, Ricardo (Eds.). Democracy. A Reader, Nueva York, Columbia University Press, 2000, p. 233.

6 Como lo expresó Lenin en su conocida obra El Estado y la revolución (1917).

7 Véase NOVOA MONREAL, Eduardo. El Derecho Como Obstáculo al Cambio Social, México D. F., Siglo Veintiuno, 1975.
} 
largos y tediosos procesos de negociación característicos de las democracias constitucionales, la toma revolucionaria del poder y sistema de partido único prometían ser mecanismos capaces de imprimirle dinamismo y expedición a un proceso de transformación económico-social que terminaría de raíz con una sociedad marcada por la pobreza, la desigualdad y la exclusión de las mayorías. Por cierto, el modelo cubano consideraba que el gobierno no tuviera mayores contrapesos institucionales, pero eso no fue considerado como algo demasiado peligroso, dado que, a fin de cuentas, la autoridad política en cuestión era el gobierno del pueblo, de los oprimidos.

La revolución cubana tuvo un fuerte impacto en buena parte de la izquierda latinoamericana, incluida la de países como Chile, donde ésta había avanzado considerablemente su agenda, e incluso accedido al poder presidencial mediante procesos democráticos. El influjo de la experiencia cubana en Chile redundó en que la mayor parte de la coalición de gobierno, la Unidad Popular, dedicó más tiempo a intentar sustituir el programa de esta última por uno más revolucionario, desperdiciando así la oportunidad de apoyar al histórico gobierno de Salvador Allende, en momentos en que éste contaba ya con formidables enemigos.

En el caso de la derecha, ella también mostró distancia -cuando no abierta hostilidad-respecto al concepto mismo de democracia constitucional. La atávica desconfianza respecto de las mayorías que la había caracterizado desde el siglo XIX, se expresó con fuerza cuando hacia mediados del siglo XX se completó el avance del sufragio universal en la región. Alarmados por el potencial de transformación social que implicaba el acceso de la izquierda al poder presidencial, en particular la redistribución de la tierra, los sectores conservadores no tuvieron mayores escrúpulos en acudir a las Fuerzas Armadas para expulsar del gobierno a autoridades elegidas democráticamente ${ }^{8}$.

Producto de lo anterior, hacia mediados del siglo XX la mayor parte de la derecha latinoamericana había tomado distancia de la democracia, sustituyéndola por nacionalismos más o menos represivos, pero siempre antidemocráticos e iliberales. Eventualmente, esta aproximación a la política devino en la llamada "Doctrina de Seguridad Nacional", que propugnaba la noción de que lo esencial era la supervivencia de la nación, objetivo que podía justificar que sectores supuestamente "virtuosos" de la misma asumieran el mando. Esta ideología miraba a la democracia como un instrumento desechable y a la doctrina de los derechos fundamentales como una concepción ingenua e individualista, que no se hacía cargo de la nación como un "organismo" esencial cuya protección podía justificar incluso el sacrificio de algunos de sus integrantes. En este contexto intelectual, revivieron antiguas doctrinas del conservadurismo latinoamericano que asumían la incapacidad de las masas para autogobernarse y la consiguiente necesidad de contar con autoridades que estén por sobre las divisiones político-partidistas, como las Fuerzas Armadas ${ }^{9}$.

Un tercer grupo que durante el siglo XX exhibió escaso aprecio por la democracia constitucional estaba formado por aquellos que propugnaban modalidades populistas y caudillistas de desarrollo. Estos tenían en común con la izquierda su rechazo a la pobreza y a las desigualdades que caracterizan a la región, y con los sectores conservadores, su matriz nacionalista e iliberal en cuestiones culturales. Si bien eran claramente partidarios de la democracia como modo de acceso al poder -después de todo, su poder se fundaba en su capacidad de seducir a las masas-, desdeñaban la

8 Estas acciones ocurrieron, por cierto, en un contexto internacional marcado por la Guerra Fría y la consiguiente disposición de muchas democracias liberales avanzadas a hacer vista gorda ante golpes militares de derecha en el Tercer Mundo. En este sentido, la coincidencia que existió entre la consolidación del sufragio universal en América Latina y la Guerra Fría fue particularmente desafortunada.

9 Para un excelente análisis de la forma en que este discurso se desarrolló en derecha chilena en tiempos de la dictadura militar del General Pinochet, véase el libro de HUNEEUS, Carlos. El Régimen de Pinochet, Santiago de Chile, Sudamericana, 2000. 
noción constitucionalista de que las autoridades democráticamente elegidas debían reconocer límites a su autoridad, como el respeto a los derechos fundamentales o la separación de poderes. Por lo dicho, el populismo latinoamericano prefería la expedición en la consecución de metas de transformación económico-social por sobre el respeto a las formas constitucionales o legales.

En síntesis, aun antes de la ola de dictaduras militares que asoló a América Latina en los años sesenta y setenta, el arraigo del ideario democrático-constitucional era extremadamente débil en la región. Esto queda especialmente de manifiesto en un episodio poco conocido -pero muy revelador- ocurrido en un país que se consideraba contaba con una de las democracias más ejemplares de la región: Chile. En efecto, mucho antes del ominoso golpe de Estado dirigido en contra del Presidente Salvador Allende, la respetada democracia chilena aprobó (en 1948) legislación que de un plumazo privó de la totalidad de sus derechos políticos (y varios de sus derechos civiles) a decenas de miles de ciudadanos por el solo hecho de haber militado en el Partido Comunista, colectividad que incluso había sido parte de la coalición de gobierno hasta poco antes del episodio que comentamos. Esta flagrante violación de los principios democrático-constitucionales se ejecutó "a plena luz del día" mediante la solemne aprobación en el Congreso Nacional de la denominada Ley de Defensa Permanente de la Democracia ${ }^{10}$ (también conocida como la Ley Maldita, por sus detractores) ${ }^{11}$. En virtud de ella, miles de militantes comunistas fueron eliminados de los registros electorales e impedidos de ejercer sus derechos de asociación, reunión y expresión. Adicionalmente muchos fueron expulsados de la administración pública.

Lo que resulta más impactante de este episodio es que las sanciones señaladas fueron establecidas por legislación aprobada por una abrumadora mayoría de los parlamentarios chilenos (con la sola excepción de un entonces pequeño partido social-cristiano y algunos parlamentarios socialistas, como Salvador Allende). Confrontada a una ley que estaba en abierta contradicción con los principios democrático-liberales que consagraba la Constitución chilena de 1925, la Corte Suprema de Justicia prefirió eludir su rol de defensa de los derechos fundamentales en un fallo que desconoció groseramente el derecho de quienes impugnaron la constitucionalidad de la ley ${ }^{12}$. Para terminar con la descripción de este episodio, cabe subrayar que la mencionada ley estuvo en vigencia por una década (hasta 1958, sólo quince años antes del golpe de Estado de 1973), periodo en que Chile siguió siendo considerado como el gran ejemplo de democracia latinoamericana.

Me he detenido en este episodio de la historia chilena porque a mi juicio refleja en toda su dimensión el escaso arraigo de los principios democrático-constitucionales en la cultura política latinoamericana, incluso en una época en que se consideraba que ésta tuvo cierto arraigo en la región. El contraste entre apariencia y realidad queda de manifiesto cuando se considera, por ejemplo, que en el mismo año en que se aprobó la mencionada "Ley Maldita" chilena, representantes de ese gobierno eran parte del selecto grupo de juristas que participaron en la elaboración de la Declaración Universal de los Derechos Humanos.

10 Ley $\mathrm{N}^{\circ}$ 8.987, de 3 de septiembre de 1948.

11 El gobernante que propició esta legislación, el radical Gabriel González Videla, lo hizo aparentemente presionado por los Estados Unidos, que por esos años se encontraba en plena competencia con la Unión Soviética por la hegemonía mundial y que había introducido una legislación similar en su propio país. Para un excelente análisis de esta ley y su impacto véase HUNEEUS, Carlos. La guerra fría chilena: Gabriel González Videla y la Ley Maldita, Santiago de Chile, Random House Mondadori S.A., 2009.

12 La acción constitucional que se menciona fue interpuesta por el abogado comunista René Jofré. Véase fallo inaplicabilidad de la Corte Suprema de Justicia de 3 de noviembre de 1948. Citado en FAÚNDEZ, Julio. Democratization, Development, and Legality: Chile, 1831-1973, Nueva York, Palgrave Macmillan, 2007. 
La desafección ideológica respecto de la democracia constitucional que, por motivos diferentes, exhibió hasta los años setenta la mayor parte de la izquierda y la derecha latinoamericana, cambiaría radicalmente en la década del noventa. En el caso de los sectores de la izquierda, el catalizador fue la brutal persecución de que fue objeto durante la ola dictatorial que inundó la región en el periodo precedente, y que se tradujo en la tortura, el desaparecimiento, las ejecuciones extrajudiciales, el exilio y otras graves violaciones a los derechos humanos, experiencia que llevó a este sector a valorar antiguas instituciones constitucionales como el habeas corpus o el debido proceso. Paralelamente, la caída y consiguiente deslegitimación de los "socialismos reales" de Europa del Este (en el periodo 1989-1990) plantearon a la izquierda la necesidad de articular una plataforma política que, manteniendo su siempre vigente crítica a la desigualdad inherente a las economías capitalistas, promoviera los derechos fundamentales del individuo como un elemento sine qua non de todo régimen político razonable. Así, la izquierda latinoamericana dejaba atrás la noción de que sin una economía socialista la democracia constitucional carecía de todo sentido.

En el caso de la derecha, los motivos de su "conversión" a los ideales de la democracia constitucional vinieron por el lado de la economía. En efecto, hacia fines de la década de los ochenta se instaló en el mundo conservador latinoamericano la noción de que el establecer un estado de derecho efectivo constituye un requisito indispensable para obtener un crecimiento económico sustentable en el tiempo. Este discurso, que fue elaborado por la denominada "economía institucional" y luego adoptado y propagado por institucionales multilaterales de crédito (como el Banco Mundial y el Banco Interamericano de Desarrollo, BID), argumenta que sin un estado de derecho sólido que establezca derechos de propiedad claros, un poder judicial independiente y una fuerza pública bien organizada $^{13}$, los países más atrasados no alcanzarán el desarrollo económico. Como incluso esta modesta concepción del estado de derecho implica la noción de gobiernos limitados, los sectores conservadores de la región comenzaron a valorar el constitucionalismo. Por otra parte, el hecho de que la Guerra Fría -y la consiguiente "amenaza" comunista- había llegado a su fin, terminó con el antiguo temor de la derecha latinoamericana respecto al sufragio universal, despejando finalmente el camino hacia su pragmática adhesión a la democracia constitucional.

\section{Luces y sombras de la experiencia democrática reciente en América Latina}

En parte final de la sección anterior se pasó lista a los diversos factores que a nuestro juicio contribuyeron a que los ideales democrático-constitucionales se impusieran en América Latina, al punto que hoy por hoy gozan de una hegemonía incontrarrestable, al menos a nivel del discurso. Por cierto, esto no significa que exista en toda la región una práctica consistente con dicha retórica. Dicho esto, incluso teniendo en cuenta la brecha entre los ideales y la práctica política concreta, es innegable que la situación actual representa un enorme avance respecto de la situación precedente, en que la mayor parte de la derecha y la izquierda latinoamericana cuestionaban desde el punto de vista conceptual o ideológico el modelo democrático constitucional.

Si bien todavía hay motivos para sospechar acerca de la genuina convicción democrática de algunos de los actuales líderes latinoamericanos, lo cierto es que en la actualidad no es viable articular plataformas políticas que sean abiertamente contradictorias con el ideario democráticoconstitucional. En efecto, es difícil imaginar que alguien pueda construir mayorías en América Latina negando la importancia de la elección mayoritaria de las autoridades políticas, el respeto a la separación constitucional de los poderes o el respeto a los derechos fundamentales del individuo. Esta nueva realidad, nos parece, representa un acervo que no debe menospreciarse. De hecho,

13 Lo que el Premio Nobel de Economía 2009, Oliver Williamson, Ilamó “las instituciones económicas del capitalismo". Véase WILLIAMSON, Oliver. The Economic Institutions of Capitalism, Nueva York, The Free Press, 1985. 
una generación de latinoamericanos ha sido educada dentro de un fuerte consenso conceptual respecto del valor de la democracia constitucional. Y eso deja su huella, haciendo más difícil aventuras autoritarias abiertas. En efecto, aun cuando algunos líderes de región no practiquen los ideales que predican, el solo hecho de proclamarlos les impide contrarrestar fácilmente críticas a acciones suyas que a todas luces se contradicen con los ideales que dicen defender. Para decirlo de forma algo brutal, la diferencia entre Corea del Norte y la Venezuela de Chávez o la Colombia de Uribe es, este sentido, gigantesca.

Dado el contexto actual, las formas de deslealtad constitucional en América Latina adquieren formas mucho más sutiles. Impedidos de embarcarse en transgresiones directas y explícitas a las libertades públicas o en otras formas de abusos de poder, los gobernantes iliberales de nuestra era actúan de manera solapada, lo que, por otra parte, demanda de observadores y fiscalizadores un escrutinio mucho más fino. Cerrado el camino del abierto desconocimiento de la democracia constitucional en aras de la consecución de objetivos como la seguridad nacional o la revolución social, las autoridades con tendencias autoritarias enfrentan mayores obstáculos para desconocer los elementos centrales del estado constitucional de derecho. El problema, sin embargo, es que las personas ven afectados sus derechos fundamentales y las instituciones democráticas se resienten aun en casos en que el desconocimiento de estos valores es subrepticio.

Hemos revisado cómo la hegemonía cultural alcanzada por la democracia constitucional en la América Latina de hoy representa un importantísimo logro. Sin embargo, paralelo a este nuevo escenario persisten en nuestros países graves violaciones de los derechos de las personas y grupos minoritarios, así como severos problemas de corrupción gubernamental y otras formas de abuso de poder. Por lo mismo, urge avanzar resueltamente en acortar la brecha entre el discurso democrático-constitucional y la práctica política concreta, no sólo porque ello representa una demanda básica de justicia, sino porque de lo contrario la propia legitimidad del modelo democrático podría deteriorarse.

Teniendo claro lo anterior, es importante ser precisos en el diagnóstico de los nudos críticos del desempeño democrático en América Latina, de manera de focalizar la energía en lo más urgente y prioritario. En este sentido, cabe preguntarse por las áreas más deficitarias de la democracia en la región, cuestión que naturalmente debe preceder el análisis de las propuestas para mejorar el estado de nuestras democracias. En esta sección, se abordan algunos problemas que han motivado interés de quienes observan el decurso de la democracia constitucional en la región, así como otros que han sido menos estudiados y que -sin embargo- debieran concentrar nuestra atención.

\section{a. La sorpresiva reducción de la pobreza y de la indigencia}

Quizá por inercia, todavía existe la generalizada impresión de que -tras dos décadas de democracia en América Latina- la pobreza y la exclusión de las grandes mayorías continúan más o menos inalteradas. Esta noción, que puede parecer de sentido común en una región tradicionalmente marcada por la pobreza es, sin embargo, incorrecta. En efecto, en los últimos veinte años América Latina ha experimentado un enorme progreso en materia de reducción de la pobreza y la indigencia.

De acuerdo a un respetado estudio de la Comisión Económica para América Latina (CEPAL), en el año 2008 las tasas de pobreza e indigencia eran sustancialmente más bajas que las existentes en el año 1990. En efecto, mientras que en ese año en la región había un 48,3\% de la población viviendo bajo la línea de pobreza, en el año 2008 ella alcanzaba a sólo un 33\% ${ }^{14}$. En el caso de

\footnotetext{
14 Véase CEPAL, op. cit., p. 10.
} 
la indigencia, la reducción fue aún más significativa, habiéndose reducido casi a la mitad, desde un $22,5 \%$ (en 1990), a un $12,9 \%(\text { en } 2008)^{15}$.

Sin caer en la complacencia -ya que no es razonable celebrar que un tercio de la población siga sumida en la pobreza - no puede desconocerse que la performance de la democracia constitucional latinoamericana en materia de reducción de la pobreza y la indigencia en los últimos veinte años es encomiable. De hecho, el mismo reporte de la CEPAL que mencionamos sostiene que, gracias al esfuerzo realizado en esta materia, América Latina se encuentra muy bien posicionada para alcanzar la Meta 1 de los denominados Millennium Development Goals ${ }^{16}$, y que consiste en reducir a la mitad el índice de pobreza que afecta a la región para el año $2015^{17}$. De acuerdo a la CEPAL, la importante reducción en los niveles de pobreza e indigencia en la región son en parte atribuibles a lo que denominan el "efecto crecimiento", y en parte al hecho de que el gasto social per cápita de los Estados se duplicó entre 1990 y 2007, coincidiendo con el periodo de estabilidad democrática que nos ha ocupado en este trabajo ${ }^{18}$.

Recapitulando, este aspecto de la evaluación del desempeño de las democracias latinoamericanas se puede concluir que, contra lo que pudiera pensarse, los veinte años de democracia constitucional en la región han tenido un positivo impacto en materia de reducción de la pobreza y la indigencia, por lo que debiera persistirse en las estrategias que se han implementado en este ámbito en las últimas dos décadas.

\section{b. La persistencia de la inequidad}

Dado que la evidencia indica que América Latina lo ha hecho bastante bien en el importante objetivo de reducir la pobreza y la indigencia, cabe preguntarse si la exclusión que siguen manifestando los latinoamericanos en diversos estudios de opinión no estará más vinculada al otro histórico flagelo que ha afectado a la región desde tiempos coloniales, la inequidad. Cuando se revisa la evidencia empírica a este respecto, ello queda confirmado. En efecto, incluso los países que lideran la lucha por reducir la pobreza y la indigencia (como Brasil y Chile) continúan exhibiendo niveles de desigualdad en el ingreso inaceptables. Como lo sostiene un reciente estudio del Banco Mundial "América Latina es una de las regiones más inequitativas del mundo, donde el $10 \%$ más rico de la población captura el $40 \%$ de los ingresos totales, y donde el $10 \%$ más pobre de la región recibe un mero $1 \%$ de los ingresos" ${ }^{19}$.

Si bien el estudio de la CEPAL mencionado anteriormente consigna cierto progreso en materia de equidad en la distribución del ingreso en relación al año 199020, el mismo estudio concluye que "[...] el hecho es que América Latina continúa exhibiendo una de las concentraciones del ingreso más elevadas del mundo" 21 .

15 Ibídem.

16 Ibídem.

17 En todo caso, el estudio de la CEPAL que comentamos precisa que la situación de reducción de la pobreza e indigencia varía considerablemente de país a país, con Brasil, Chile y Costa Rica liderando el grupo de países que más avanzaron en reducir la pobreza dentro de la región.

18 Como ocurría con la disparidad entre distintos países latinoamericanos en materia de reducción de la pobreza y la indigencia, también en términos de gasto social se advirtieron importantes diferencias con países que al interior de la región exhiben un gasto social 20 veces mayor que el de otros.

19 Véase "World Bank Reports On Inequality In Latin America" (viernes 3 de octubre de 2008). http://www.scoop.co.nz/ stories/WO0810/S00075.htm.

20 De acuerdo al estudio de la CEPAL "La distribución del ingreso mejoró en comparación con el año 1990, con una disminución promedio del coeficiente de Gino de 4\%". Véase CEPAL, op. cit., p. 12.

21 Ibíd., p. 11. 
Como se desprende de la evidencia empírica ya mencionada, a pesar de veinte años de democracia -y de haber avanzado muchísimo en reducir el hambre y la pobreza- América Latina continúa siendo una zona marcada por profundas y persistentes inequidades. Más desalentador aún es que la desigualdad persiste a pesar de la virtuosa combinación de políticas económicas que fomentaron el crecimiento y las que aumentaron sustancialmente el gasto social, lo que sugiere que se necesitan otras políticas para abordar este crónico problema. Aquí cabe destacar que es mucho más difícil reducir la inequidad en los ingresos que elevar la calidad de vida de indigentes y pobres a un estándar mínimo. Dicho esto, la aguda desigualdad que caracteriza a América Latina representa uno de los mayores peligros que enfrenta la estabilidad democrática en la región.

\section{c. La ejecución masiva de la "clase criminal"}

Si existe algo que debiera haber cambiado radicalmente con el término de las dictaduras militares es la ejecución de personas a manos de agentes del Estado. En efecto, aún en sociedades tan inequitativas como las de América Latina, la democracia, con todas sus imperfecciones, debiera haber sido capaz de ofrecer a todos sus habitantes la garantía de que el derecho a no ser eliminado por la fuerza pública sería respetado por quienes detentan, a nombre del pueblo, el poder coercitivo del Estado. Sin embargo, y aunque parezca increíble, muchas de las democracias latinoamericanas no han sido capaces de garantizar que las fuerzas de seguridad pública respeten ese derecho humano tan fundamental. Como lo consigna un importante trabajo de Daniel Brinks ${ }^{22}$, en dos importantes países de la región (Brasil y Argentina) la policía ejecutó entre 1990 y 2000 a varios miles de personas en incidentes que fueron luego descritos oficialmente como "enfrentamientos entre la policía y delincuentes" o "intentos de detener la fuga de un detenido"23. Añadiendo escándalo a los ya aberrantes hechos descritos, los perpetradores fueron rara vez condenados por su responsabilidad en estos crímenes de Estado.

A pesar de lo grave y extendido que han sido los asesinatos policiales en algunas de las democracias de la región, ellos han recibido escasa difusión, quizá porque -a diferencia de lo ocurrido en la era autoritaria- el motivo de las ejecuciones no es político, sino que se enmarca dentro de la llamada "guerra contra el crimen", en el contexto de un efectivo aumento de la delincuencia en América Latina y de un clima de opinión que propicia una endurecimiento de la respuesta oficial contra aquella. Así, dado que quienes han caído se supone pertenecen a "la clase criminal", el escándalo que debiera generar el gran número de ejecuciones policiales no se ha producido.

Como lo consigna con lucidez Brinks, una de las razones por las cuales ha sido tan difícil que incluso democracias como la brasileña o la argentina terminen con la escandalosa situación de los asesinatos policiales, es la generalizada impunidad de que gozan los perpetradores, la que se relaciona, primero, con el hecho de que son las propias policías las que deben investigar estos casos -lo que genera un evidente conflicto de interés-, y en segundo lugar porque como las víctimas pertenecen a los grupos más desposeídos sus demandas por justicia en estos casos tienen menos

22 Véase BRINKS, Daniel. The Judicial Response to Policy Killings in Latin America. Inequality and the Rule of Law, Cambridge, Cambridge University Press, 2008.

23 Hasta la publicación del estudio de Brinks, había cierta conciencia de que en América Latina la policía era en ciertos lugares corrupta e ineficiente. Incluso, se sabía de que en ciudades como Río de Janeiro o Sao Paulo era habitual el asesinato de jóvenes pandilleros por parte de bandas armadas y algunos policías. El mencionado trabajo de Brinks reveló, sin embargo, que la ejecución de personas asociadas a las "clases criminales" era mucho más generalizada y masiva de lo que se pensaba, alcanzando a la friolera de 7.500 personas asesinadas por la policía sólo en la ciudad de Sao Paulo en el periodo 1990-2000 y a las 1.755 en la Provincia de Buenos Aires. No tenemos evidencia comparable para Centroamérica y otos países de América del Sur, pero hay buenas razones para pensar que la situación no es demasiado diferente. 
resonancia en la sociedad. Finalmente, no debe descartarse que el clima de opinión generado por la propagación del Ilamado "populismo punitivo" (que aboga por una mano "más dura contra la delincuencia") influya en la tolerancia a este tipo de prácticas tan inhumanas.

Mirado en perspectiva, las masivas ejecuciones de ciudadanos por parte de la policía representan uno de los más serios problemas de derechos humanos de la democracia latinoamericana, ya que afectan al más fundamental de los derechos de las personas. Dicho esto, existen abismales diferencias en la incidencia con que este flagelo se da en los distintos países de la región, ya que, por ejemplo, en paralelo a la difícil situación que presentan en este ámbito tanto Brasil como Argentina, Uruguay exhibe ínfimos casos de esta aguda forma de violencia policial. Asimismo, en este último país, los pocos casos que ocurren son, en general, investigados y los perpetradores condenados. De ahí que haya base para esperar que las buenas prácticas de países como Uruguay se transmitan a aquellos en que la situación es insostenible.

\section{d. Corrupción y la falta de transparencia}

Otro de los puntos negativos de la performance de las democracias latinoamericanas es el aparente agravamiento de la corrupción, tanto de las autoridades públicas, como en el sector privado. En efecto, es un hecho conocido que América Latina se encuentra en los niveles más bajos de los índices de transparencia (con un par de excepciones). Dicho esto, es imposible saber si desde 1990 al 2000 la situación de la corrupción pública y privada ha aumentado o ha disminuido, ya que los estudios sobre transparencia en la región comenzaron a realizarse hacia fines de los años noventa. Como lo sugieren Martuccelli y Sorjj ${ }^{24}$, los cambios culturales relacionados con propia extensión de la democracia han reducido la tolerancia de la ciudadanía frente a la corrupción, por lo que no debe descartarse que, en lugar de un aumento neto en las prácticas corruptas en América Latina, lo que en realidad ocurre es una mayor disposición de la ciudadanía a denunciarlas. Complementando este aspecto cultural, en los últimos años han proliferado en la región leyes de transparencia, probidad y acceso a la información pública, elementos que también contribuyen a visibilizar casos que antes pasaban desapercibidos.

Aun considerando que lo anterior sea efectivo, sigue siendo cierto que, comparada con la situación de probidad y transparencia de las democracias avanzadas, los niveles de corrupción pública y privada son demasiado altos en América Latina. En este contexto, se debiera avanzar en una cultura política más proba y en el establecimiento de mecanismos institucionales como controles, supervigilancias y otros, que dificulten la consumación de actos de corrupción.

\section{e. Los derechos de las mujeres y de las minorías indígenas y sexuales}

Como lo han venido consignando periódicamente numerosos estudios que cada año publican las organizaciones no gubernamentales y del sistema de Naciones Unidas sobre el estado de los derechos humanos en América Latina, a pesar de que durante los últimos veinte años se han producido importantes avances, los derechos de las mujeres y de las minorías indígenas y sexuales continúan siendo sistemáticamente postergados -cuando no directamente violentados- por las democracias de la región. Antiguos prejuicios culturales conspiran en contra de mayores avances, a lo que se suma la débil respuesta de los Estados ante la presión de la sociedad civil (nacional, regional y global) por avanzar más decididamente. Como en el caso del combate contra la pobreza

24 Véase SORJ, Bernardo y MARTUCCELLI, Danilo. El Desafío Latinoamericano: Cohesión Social y Democracia, Buenos Aires, Siglo XXI, 2008. 
y la indigencia, el grado de formación del estado nacional del país involucrado es un influyente factor en este ámbito.

Con todo, es innegable que en las últimas dos décadas se han registrado avances que habrían sido difíciles de imaginar en la década de los ochenta en materia de reconocimiento constitucional de los pueblos indígenas y minorías sexuales, así como en relación a la equidad entre mujeres y varones. Dicho esto, y como sucede en otros ámbitos en América Latina, el problema suele ser pasar de la retórica constitucional (o legal) a la práctica administrativa.

\section{f. La consolidación de la idea de derechos económicos y sociales}

Uno de los desarrollos importantes que se produjeron en materia de derechos en estos veinte años de democracia en América Latina es la penetración de la doctrina constitucional que sostiene la equiparidad y complementación entre los derechos civiles y políticos clásicos y aquellos de "segunda generación", como los de naturaleza económica y social. Si bien es cierto esta doctrina se encuentra más asentada entre los especialistas en derechos humanos, recientemente se ha consolidado también entre los constitucionalistas de la región, aunque todavía no entre los economistas y expertos en políticas públicas, que suelen considerar los derechos sociales como "políticas" y no "derechos" stricto sensu.

Un problema adicional en este campo ha sido la dificultad de implementar estos derechos en países de la región que cuentan con Estados precarios y que, por tanto, tienen dificultades en recaudar lo suficiente como para llevar a la práctica estos derechos. Otro dilema que enfrentan algunos países de América Latina en relación a este ámbito, es priorizar programadamente entre los derechos sociales, evitando que sea la litigación la que decida por el Estado.

\section{Buscando respuestas: entre el retorno al caudillismo y un modelo "reforzado" de estado democrático de derecho}

A pesar de que el estado de la democracia constitucional en América Latina exhibe tanto luces como sombras, el progresivo agotamiento del encanto inicial con que los latinoamericanos recibimos la democracia ha sido reemplazado en muchos países de la región por un abierto desaliento y frustración respecto del desempeño de la misma. Si bien la situación todavía no alcanza niveles alarmantes, que amenacen con hacer colapsar el sistema democrático, el panorama se percibe lo suficientemente ensombrecido como para que muchos se afanen en articular un nuevo "modelo"de democracia para Latinoamérica.

Una de las respuestas a la generalizada impaciencia ante los magros resultados que exhibe la democracia constitucional en la región es un modelo de democracia radical que pretende no estar constreñido por ataduras constitucionales como la separación de poderes o la irrestricta libertad de expresión de los opositores (como fue el caso de Fujimori en Perú, y el de Chávez en Venezuela y, en menor medida, Uribe en Colombia). Este modelo, que en realidad no tiene nada de novedoso ya que no es demasiado diferente al viejo caudillismo latinoamericano centrado en el mesianismo y el carisma del líder como "salvador de la patria", cae en la ilusión de que "tomando un atajo" -esto es, saltándose las formas constitucionales- se logran con rapidez los objetivos. Lo que sus partidarios no advierten, sin embargo, es que al sacrificar las instituciones para obtener un resultado inmediato se hipoteca la posibilidad de un desarrollo político y económico sustentable en el tiempo.

Dependiendo de las circunstancias, este tipo de populismo adquiere un cariz de izquierda o de derecha. Así, cuando la sociedad de que se trate está enfrentando una crisis de orden y seguridad 
(como ocurrió en Perú y en Colombia), el modelo adquiere un matiz conservador, satisfaciendo, por decirlo de alguna manera, la pulsión "hobessiana" de la población. Por otra parte, cuando la sociedad de que se trate goza de niveles razonables de orden y seguridad pero está marcada por la desigualdad y exclusión, surgen líderes que prometen una rápida redistribución, aunque ello signifique sacrificar otros valores constitucionales.

Más allá de sus diferencias, lo que ambos tipos de populismo tienen en común es su dificultad de asegurar su reproducción en el tiempo, por lo que suelen terminar en la perpetuación del líder carismático, lo que termina generando problemas que eventualmente derivan en el violento colapso del precario orden que construyeron. Aunque en ocasiones este tipo de regímenes obtienen avances notables en materia social, normalmente tienen dificultades en sostener las mismas en el tiempo.

Desde la orilla opuesta a este tipo de modelos iliberales, la más interesante propuesta ha sido la propiciada por el Ilamado "neoconstitucionalismo" 25 , que propone un modelo de Estado caracterizado por la eficacia directa y la justiciabilidad del más completo catálogo de derechos constitucionales concebible, esto es, uno que incluya todos los derechos civiles, políticos, económicos, sociales y culturales consagrados por los instrumentos propios del derecho internacional de los derechos humanos así como en el ius cogens. De acuerdo a esta aproximación al problema, sólo este tipo de estado de derecho "reforzado" e implementado además por jueces progresistas imbuidos de los valores y principios del estado social de derecho, logrará que la empobrecida democracia latinoamericana esté a la altura de las enormes expectativas que hemos depositado en ella.

El modelo al que aludimos se presenta a sí mismo como uno que pretende ser coherente con las teorías deliberativas de la democracia, arguyendo, por tanto, que una verdadera democracia supone que todos los ciudadanos tengan la posibilidad real de acceder al ejercicio deliberativo en igualdad de condiciones. Como para que ello ocurra es necesario que todos los individuos tengan plenamente satisfechos sus derechos fundamentales -continúa el argumento- una genuina democracia tiene como prerrequisito básico la satisfacción de todos los derechos fundamentales de las personas. Así, en lugar de apostar a que sea la democracia la que contribuya a hacer efectivo un catálogo cada vez más ambicioso de derechos, se da vuelta el argumento y se sostiene que la satisfacción de esa muy demandante lista de derechos es un prerrequisito de la democracia.

25 De acuerdo a Eduardo Aldunate, los rasgos comunes de las diferentes corrientes neoconstitucionales son las siguientes: “a) el surgimiento de constituciones dotadas de garantías jurisdiccionales, en especial para asegurar la vigencia de los derechos fundamentales y, en general, la concreción de la Constitución como norma de eficacia directa (carácter vinculante); b) el desarrollo, en la aplicación práctica de los mecanismos de tutela jurisdiccional, de un efecto de irradiación de la Constitución al ordenamiento jurídico subconstitucional (constitucionalización del derecho), que cuando se produce en el ámbito de los derechos fundamentales se trata bajo el tópico del efecto horizontal de los derechos fundamentales; c) la recepción en el texto, la jurisprudencia y la doctrina, de valores constitucionales, y dentro de ellos, en primera línea, los derechos constitucionales que pasan a ser considerados "principios" o mandatos de optimización, y que por tanto exigen en su aplicación por el operador jurídico; d) el desarrollo de un método de ponderación para asegurar que su afectación haga en todo caso compatible el respectivo derecho con otros derechos o bienes constitucionales; o, al menos, de algún otro método que se presente (y se presenta) como declaradamente opuesto al positivismo jurídico; e) como último aspecto destacable de esta evolución, la imbricación del sistema constitucional dentro de sistema supranacionales, ya sea como procesos propios (en el caso europeo) ya sea al menos como inserción dentro de un régimen de protección internacional (regional o universal) de los derechos humanos. Este último es, precisamente el caso de la Unión Europea, donde el discurso neoconstitucionalista ha explorado en combinación con la filosofía política postmodernista y la politológica del "gobierno multi nivel" la extensión de las categorías propias del constitucionalismo a los ámbitos políticos exteriores al Estado y tradicionalmente vinculados a la lógica internacionalista". Véase ALDUNATE, Eduardo. Neoconstitucionalismo: Aproximación a una etiqueta y discusión de contenidos. En: Coloquio de Justicia Constitucional, Santiago de Chile, Facultad de Derecho, Universidad Diego Portales, junio de 2009, pp. 1-2. Documento en poder del autor. 
Si bien la reconstrucción que hemos hecho del argumento neoconstitucional puede ser injusta en su simpleza, es difícil evitar la conclusión de que este modelo tiene un fuerte sello utópico, que aparece en evidencia cuando se advierte que -para ser consistente con su modelo- un neoconstitucionalista debería llegar a la peculiar conclusión de que, dado que no se conoce sociedad alguna en que todos los habitantes gocen de todos sus derechos (civiles, políticos y económicos sociales y culturales), no existiría ni una sola democracia genuina en el planeta.

Mirado con benevolencia, no hay nada de malo en un modelo que sostiene que ninguna democracia "real" es digna del apelativo. De hecho, el plantearse una vara tan elevada para alcanzar el estatus de una genuina democracia deliberativa podría constituir un estímulo para que las "democracias reales" se acercaran lo más posible al ideal. Lo que se echa de menos, sin embargo, son herramientas analíticas para identificar los indicadores básicos que permitieran distinguir -al interior del universo de democracias imperfectas- entre aquellas en que, por ejemplo, el Estado no elimina a sus ciudadanos, de otras que sí lo hacen.

Otro problema del modelo neoconstitucionalista es que carece de una teoría acerca de la relación que existe entre instituciones que, a pesar de tener mucha afinidad son, sin embargo, analíticamente distinguibles entre sí, como ocurre con el "estado de derecho" en sentido estricto (el rule of law inglés), el "constitucionalismo" y la "democracia". Lo que ocurre es que, en su afán por lograrlo "todo, aquí y ahora", el neoconstitucionalismo no diferencia entre las tres instituciones mencionadas, colocándolas todas dentro del mismo "saco" virtuoso que propicia. Esta incapacidad para distinguirlas, a su vez le impide articular una teoría acerca de cómo -y en qué secuencia- se podría avanzar hacia la consolidación de esta constelación de valores e instituciones. En efecto, el modelo neoconstitucional parece fusionar las tres instituciones en una, que rotula "estado social y democrático de derecho".

Un ejemplo que ilustra el problema de no distinguir analíticamente entre la constelación de valores que nos ocupa es, por ejemplo, la compleja relación que existe entre la justicia constitucional (elemento característico del "constitucionalismo duro") y la independencia judicial (aspecto central del más elemental rule of law o "estado de derecho"). Como hemos argumentado en otra parte ${ }^{26}$, en los países de América Latina históricamente ha costado mucho consolidar una judicatura razonablemente independiente del Ejecutivo, aspecto esencial en una región en que -como vimos anteriormente en relación a los asesinatos policiales- el Poder Ejecutivo es el más frecuente perpetrador de violaciones a los derechos humanos (tanto en dictadura como en democracia). En efecto, sólo una judicatura independiente del gobierno puede ejercer efectivamente un control de la legalidad de los actos de administración, que es precisamente el mecanismo más eficaz para proteger a los individuos de los actos abusivos del gobierno. Pues bien, de acuerdo a la lógica institucional del presidencialismo, cuando la judicatura controla la conformidad de los actos administrativos del gobierno con la ley, ella está "trabajando" para el Poder Legislativo, ya que la ley es a fin de cuentas un producto generado por ella. De ahí que cuando un juez se enfrenta a un Ejecutivo que pretende pasar a llevar la ley, sabe que podrá contar con el respaldo del Legislativo en su enfrentamiento con el gobierno.

El problema surge cuando -con las mejores intenciones- el neoconstitucionalismo promueve que la judicatura asuma además un muy activo rol en el control de la constitucionalidad de las leyes. Este tipo de control -por su propia naturaleza- pone a la judicatura no sólo en contra del Ejecutivo, sino que además en contra del Legislativo que, como vimos, es su gran apoyo cuando vela por la adecuación de la actuación presidencial a la ley. En efecto, cuando una corte decide anular

26 Véase COUSO, Javier. Consolidación democrática y Poder Judicial: Los riesgos de la judicialización de la política. Revista de Ciencia Política XXIV (1), 2004. 
una ley por considerarla inconstitucional, en la práctica se pone en contra de los dos poderes del Estado involucrados en la gestación de la ley (el Legislativo y el Ejecutivo), lo que la deja en una precaria situación, especialmente en democracias todavía no consolidadas.

Por otra parte, el enorme poder político que le otorga a la judicatura el tener la última palabra en disputas acerca de la constitucionalidad de las leyes genera fuertes incentivos en los poderes Legislativo y Ejecutivo para intentar "hacerse" de la judicatura, lo que inevitablemente deviene en la politización de la justicia, que es una de las formas que toma la falta de independencia de los tribunales en América Latina. Así, cuando se intenta expandir aceleradamente el ámbito de control de las cortes, otorgándoles el poder de controlar la constitucionalidad de las leyes, paradójicamente se corre el riesgo de que la judicatura pierda la independencia que tenía y que le permitía ejercer el mucho más modesto -pero quizá más urgente- control de la legalidad de los actos de la administración.

Los cuestionamientos hechos a los efectos no deseados que en América Latina ha tenido en ocasiones la expansión del poder de la judicatura al ámbito constitucional no son conceptuales. De hecho, es perfectamente posible que en otras latitudes (o incluso en Latinoamérica en un futuro lejano) sea posible para las cortes preservar su independencia del gobierno y del Legislativo a pesar de contar con el formidable poder político involucrado en poder echar abajo legislación laboriosamente negociada por el Congreso y el Ejecutivo. Por lo dicho, no se trata de cuestionar conceptualmente que los jueces amplíen el ámbito de sus controles a la constitucionalidad de la ley, sino que de constatar el hecho que -en el rudo mundo de la política latinoamericana- en ocasiones propuestas bien intencionadas tienen efectos no deseados que deben incluirse en el análisis.

El punto recién planteado se relaciona con otro problema del modelo neoconstitucional: su ceguera ante lo que Isaiah Berlin denominaba "la colisión de valores", esto es, la trágica incompatibilidad entre dos o más valores igualmente valiosos. Así, por ejemplo, uno sospecha que el neoconstitucionalismo apuesta a que no hay conflicto entre terminar con la indigencia y avanzar en la equidad. No obstante, en la práctica concreta de las políticas públicas los países se enfrentan a diario con el hecho de que atacar la pobreza en ocasiones impide avanzar más decididamente en la reducción de la inequidad. Otro ejemplo en que en los hechos existe un choque de absolutos, se da en el dilema entre dirigir recursos a terminar con la escandalosa realidad de los homicidios de miles de ciudadanos por parte de la policía en democracia y el avanzar en la implementación del derecho a una educación multicultural u otros derechos culturales similares. El sentido común sugiere que es clave priorizar y que el terminar con la ejecución de individuos por parte de quienes detentan a nombre del pueblo los medios de coerción del Estado debiera tener prioridad. En efecto, en nuestra realidad humana restringida por presupuestos limitados, energías gubernamentales acotadas y agendas legislativas apretadas, el choque de absolutos de que hablaba Berlin se da cotidianamente. Y un modelo razonable de estado democrático de derecho debiera ser capaz de dar cuenta de estos conflictos, ojalá dando orientaciones al respecto.

Pues bien, el problema con este modelo neoconstitucional es que al intentarlo todo y de inmediato, no prioriza. Como lo ha planteado el profesor chileno Eduardo Aldunate ${ }^{27}$, cuando todos los derechos son fundamentales en cierto sentido ninguno lo es. El problema que subyace a la impaciente pulsión por constitucionalizarlo todo (y esperar que jueces nacionales e internacionales decreten el alivio inmediato de todo tipo de transgresiones a un siempre creciente catálogo

27 Véase ALDUNATE, Eduardo. ¿Cuantos derechos resiste la Constitución? En: Seminario: ¿Una Nueva Constitución para la República?, Santiago de Chile, Facultad de Derecho de la Universidad Diego Portales, agosto de 2009. Texto en poder del autor. 
de derechos fundamentales), es la inhabilidad de advertir que, en ocasiones, en este mundo de recursos y energías limitadas, se requiere priorizar, porque al menos en el corto plazo, algunos objetivos son competitivos entre sí.

\section{Conclusión}

En este ensayo he intentado aquilatar tanto los progresos como los déficits en materia de gobernabilidad democrática en América Latina, al cumplirse ya dos décadas desde que la región se embarcara en procesos de transición democrática. El ejercicio arroja algunos logros innegables, como la consolidación de la democracia constitucional como único mecanismo legítimo de gobierno a los ojos de los latinoamericanos y la sensible reducción en los niveles de pobreza e indigencia entre 1990 y 2008.

Asimismo, el balance muestra que nuestros sistemas democráticos exhiben todavía severas limitaciones, como la persistencia en no pocos países de la región de prácticas que uno esperaría encontrar sólo en el contexto de dictaduras brutales (como la eliminación de miles de individuos por parte de organismos policiales) y la porfiada persistencia de niveles intolerables de inequidad y exclusión.

Una vez revisado el panorama de la trayectoria de la democracia constitucional en América Latina se analizaron dos frecuentes respuestas a la sensación de crisis de la democracia en la región: la tentación populista (de derecha o de izquierda) y la propuesta "neoconstitucional" de modelo de estado social y democrático de derecho, concluyéndose que éste resulta ser utópico en sus exigencias, e incapaz de entender que en ocasiones existe un choque de objetivos igualmente valiosos que obligan a priorizar objetivos en lugar de proclamar la urgente necesidad de establecer de inmediato la vigencia de un orden inobjetable.

Más que nuevos modelos, pareciera ser que la profundización de la democracia constitucional en América Latina pasa por el gradual y laborioso camino de insistir en institucionalizar prácticas ya conocidas (como los controles recíprocos entre los poderes del Estado, la movilización de la sociedad civil y la independencia de la judicatura), pero que cuesta mucho implementar. Asimismo, todo indica que -como en muchas cosas de la vida- se deben priorizar los recursos políticos, institucionales y económicos a objetivos urgentes y cruciales que puedan servir de base para avanzar hacia objetivos más ambiciosos. También sería útil que los diferentes países de la región miraran de vez en cuando hacia sus vecinos y aprovecharan las experiencias de países que, con historias y contextos parecidos, han logrado progresar allí donde otros han fallado. 
